\title{
Managing the Triangular Bond of the EBP for SQU Students Through the Proposed Test Model
}

\author{
Iman Al-Kindi, Zuhoor Al-Khanjari, Jamal Al-Salmi
}

\begin{abstract}
Smart city technologies are becoming dominant. One of the important pillars of a smart city is education. All citizens are learners in the smart city. To fulfill goals of a smart city, supported technology should be boosted. As a result of incorporation with the growing Information and Communication Technologies (ICT) along with software and hardware, learning environments have undergone numerous changes. Students and strategies represent the center point while adopting the online learning environment. This paper highlights important issues to shape electronic education. It considers Moodle-LMS to figure out the triangular relationship between the engagement, behavior and performance (EBP) of Sultan Qaboos Uinversity (SQU) students in any course. Moodle collects students' information and generates students' profiles. Researchers could analyze students' profiles to findout relationships between different attributes (i.e. EBP). This could guide instructors to know how engagement and behavior could be used as an indication to improve students' overall performance. This paper aims to suggest a test model intended to guide instructors to prepare personalized materials that suit individual students needs and overcome their deficiency towards a better performance. Another objective is to integrate the proposed model within Moodle environment. This paper uses data of 14 students from a fully online course at SQU. This is used to explore whether patterns of student engagement and behavior are correlated with student performance. Findings reveal the existence of a positive relationship between EBP attributes. Authors recommend instructors to use students' results to recognize students who need additional support in a specific course.
\end{abstract}

Keywords: Student Engagement, Student Behavior, Student Performance, Learning Object, Moodle, Logfile.

\section{INTRODUCTION}

T There is no doubt tha students in the snart city are seen have applied various theories, which collect and unite cognitive together with perspectives in social education.

Revised Manuscript Received on October 25, 2020.

* Correspondence Author

Iman Al-Kindi*, Department of Computer Science, College of Science, Sultan Qaboos University, Muscat, Sultanate of Oman. Email: m109107@student.squ.edu.om

Zuhoor Al-Khanjari, Professor, Department of Computer Science, College of Science, Sultan Qaboos University, Muscat, Sultanate of Oman. Email: zhuoor@squ.edu.om

Jamal Al-Salmi, Assistant Professor, Department of Information Studies, College of Arts and Social Sciences, Sultan Qaboos University, Muscat, Sultanate of Oman. Email: alsalmij@squ.edu.om

(C) The Authors. Published by Blue Eyes Intelligence Engineering and Sciences Publication (BEIESP). This is an open access article under the CC BY-NC-ND license (http://creativecommons.org/licenses/by-nc-nd/4.0/)
Meanwhile, the students' performance, student behavior and student engagement are vital whenever the academic year data is available. For example, the achievements of students in completing their course tasks and both class participation and engagement are essential factors in enhancing the learning environment. The complete learning environment needs to be efficient and follow a certain learning management style. This is more effective as a way of enhancing smart city education [1]. According to past years' perspective, there has been much attention focusing on issues of students, learning curriculum and strategies of delivering instructions [2]. For example, it has been noticed that students have different learning approaches and styles of various subjects. Learning to be a success requires inspiring students to achieve the learning outcomes they want to reach [3]. But, not all students can determine the preferable materials suitable for them, in which they can follow a path that is useful for learning by themselves [4]. Meanwhile, if a particular student does not like or feel motivated when learning something, the results of the learning may not reach the required goals.

If it is possible to understand students' behaviors as they perform different learning activities clearly, it would be much more comfortable to enhance the development of learning. From this point, it is seen that a smaller number of instructors focus on the learning behaviors of students through collecting and analyzing their learning profiles. Through the performance and engagement of every student, it would be possible to adjust students teaching techniques and be able to take any necessary precautions to enhance learning environments. Modular Object-Oriented Developmental Learning Environment (Moodle) gathers a large amount of data about students that can be used to evaluate every single action of students. It tracks each student's activity, such as downloading materials, submitting assignments, taking exams, etc. Many learning management systems come with a database that contains different types of data: user profile, log file, etc. Although there are some LMSs that include forms of their usage report, those reports are only showing the abstract level of information of students. On the other side, Moodle as LMS, provides some monitoring tools. But, it does not offer features that allow instructors to evaluate the engagement of students directly with the course activities and how it affects their learning process [5]. It prohibits instructors from making meaningful sense of using this information based on experience [6]. Higher education institutions have students with diverse needs; such institutions must have a tailor-made learning

Published By:

Blue Eyes Intelligence Engineering and Sciences Publication

(C) Copvriaht: All riahts reserved. 


\section{Managing the Triangular Bond of the EBP for SQU Students Through the Proposed Test Model}

environment and customized learning material based on student preferences [7]. This paper aims at proposing a test model process to be able to control the actions of students and predict student's behavior and engagement in any course.

Besides, it explores learning objects as a way of assisting the students and providing personalized material to individual students. Enhancing the current Moodle will motivate students to better engage in online courses. This paper would lead to the development of a smart learning environment. The paper sought to:

1. Study the relationship between the number of activities in the course for each student and the total mark.

2. Reuse the existing open source Moodle LMS and integrate it with the model to be more adaptive to student's needs.

This paper is divided into seven sections: introduction, literature review, case study, the proposed test model, method, enhancement of student using Reusable Multipurpose Learning Object Model (RMLOM) and conclusion. behavior and engagement in the learning environment and objective of the study, the literature review highlights the previous studies that have examined student engagement, behavior and performance. The case study section describes the used sample with all its components, which the authors used in this paper. Then, the authors highlighted the proposed test model, following the method and results. Also, efforts have been made to enhance student performance using (RMLOM). Finally, in the last section conclusion has been drawn.

\section{LITERATURE REVIEW}

New conceptual theories of student engagement have raised concerns about how to measure student engagement and how engagement varies not only through classes but also within online courses. Student engagement is important for student learning, particularly in the online setting. Both instructors and researchers need to be able to assess student participation (i.e. engagement) by correlating student engagement self-reports (via OSE) with student behavior monitoring data from an online course management program. In 2015, Dixson studied online student engagement (OSE) scale verification. It hypothesized that student participation in the OSE would be substantially associated with two forms of student learning behaviors (i.e. Watching lectures content) and application learning behaviors (i.e. taking quizzes) [8]. In 2016, Guilloteaux adopted a perspective on flow theory to examine the degree of learning engagement of 224 Korean students and the factors that can influence their variances in engagement. During each of the three lessons studied, each student was sampled twice at random. Engagement levels were evaluated with student's evaluation of the quality of their activities and contextual factors [9]. In 2017, Manwaring and colleagues explored student activity-level engagement at the university level in mixed learning classes. They used "structural equation modeling" to better understand the learning environments, inclusive course design and student experiences of learning [10]. In 2018, Nguyen and his
Where the introduction provides a summary of student

colleagues discussed student engagement based on three categories: disengagement, active engagement, and passive engagement. They analyzed how student behavioral engagement has changed based on the course content [11].

In addition, Hussain and colleagues used machine learning algorithms to classify low-engagement students in one selected course at an Open University to assess the impact of engagement on student's performance. The research input variables included the final student results, performance ranking and the number of clicks on the virtual learning environment. Also, their research examined the relationship between student engagement and course assessment rating [12]. Moreover, Mirriahi and colleagues used a form of learning analytics to investigate how university teaching personnel are interested in a professional development course with a collection of prescribed videos and video annotations. The findings included a comprehensive analysis of the evolution of learner interaction that can easily be translated into action to enhance the consistency of the learning experience [13]. Student engagement increases the motivation of students to learn, decreases the sense of loneliness, which increases the performance of students in online courses [14]. The design of training courses allows instructors to explore various learning styles in LMS. Formally and informally, training students can increase awareness, including online learners and train therapists in their professional practice for the use of technology. In 2019, Wasik and colleagues offered innovative approaches through their analysis in which instructors should follow when developing classes, building a classroom group, and interacting with students in an online course [15]. The aim of Lee and colleagues was to create an instrument for measuring student engagement in E-learning environments. 737 Korean online university students were the participants of the study. On the 24-item scale, six variables appeared, including social motivation, peer engagement, problem solving, and engagement with teachers, community support, and learning management. It is expected that this scale will help instructors to enhance student engagement in E-learning courses and eventually discourage students from dropping out of courses [16]. In this paper, the authors investigate student engagement in a series of activities in one course selected as a pilot study and examine whether student engagement affects student performance or not. The authors use a case study approach to get the results. Based on the received results, authors recommend using Reusable Multipurpose Learning Object Model (RMLOM) to enhance personalized learning for each student.

\section{CASE STUDY}

The teaching method at Sultan Qaboos University (SQU) is primarily based on a mixed learning approach, in a way that is integrated with both Online and Face-to-Face approaches [17]. Learning Management Systems (LMSs) is an integral part of mixed learning [18]. Specifically, in SQU, the Modular

Published By:

Blue Eyes Intelligence Engineering and Sciences Publication 
Object-Oriented Developmental Learning Environment (Moodle) is one of the LMS platforms that are used in the learning and teaching process by introducing blended courses along with face to face teaching.

It is a free, open-source learning management framework that has widespread use as a virtual learning environment in various universities [19]. It accumulates large quantities of data that can be used to test the students' behavior. It records the activities of any student, such as uploading reports and communicating with peers [20]. The authors of this paper propose a new model, which is supposed to help in tracking the student's activities in one of the selected courses as a pilot case study. The proposed test model goes through a specific process starting from student engagement, then student behavior followed by the student performance and ending with the preparation of personalized learning. In the following sub-sections, more details will be provided about the proposed model.

\section{A. Sample}

This section examines how students engaged in a fully online course and how student engagement patterns were associated with the student's performance. It was done with the aid of a sample as "Running Example" consisting of 14 undergraduate students enrolled at the "Search Strategies on the Internet" course, which was for the first time released in Fall Semester 2018 by the Department of Information Studies, College of Arts and Social Sciences at SQU. This course was the first fully electronic course to be released at SQU. Every part of this course was given electronically, including classes, reports, assignments, participation, discussions, mid-term exams, and a final exam. The course aimed to enhance students' skills in searching for information sources using different tools such as search engines, subject directories, libraries catalogs, and online databases. Fig.1 below shows the interface of the course in Moodle.

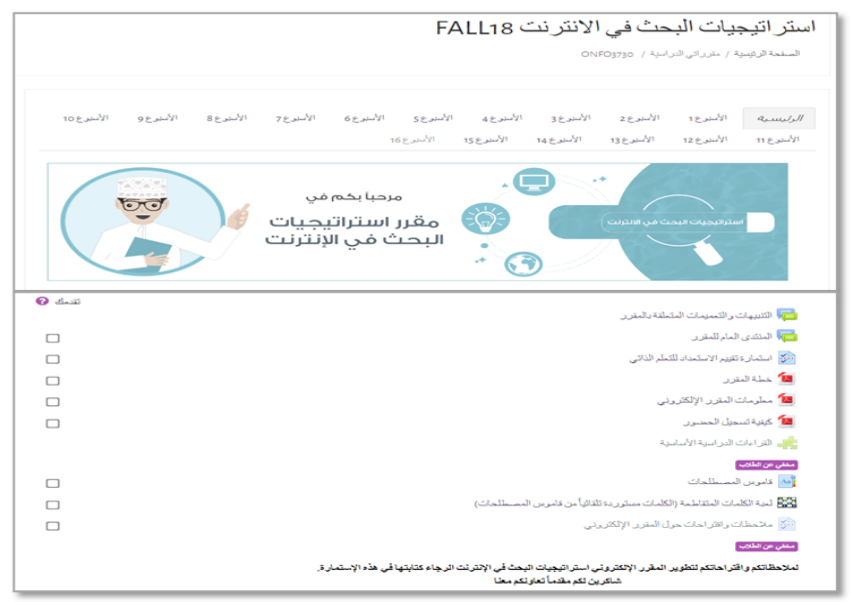

Fig. 1. Search Strategies on the Internet Course Interface in Moodle LMS in SQU.

Way of giving this course

Subjects in this course were given week by week, so students can learn and get the required skills in a smooth and a sequence way. Each week, students must watch the recording of the subject as well as read a PDF file or watch YouTube supporting clips. Each week materials were shown on Sunday morning and students had 24/7. Access to and engage in weekly discussions on these contents.
The week after, a new subject was released and the materials of last week were kept available to students. The only exception was that students were disabled from adding further discussions for previous weeks. This way forced students to follow the course week by week since participation in discussions had a grade of 20 marks (20\%). In addition to this, students could not move to the week after unless they finished all tasks related to the previous week. Moreover, they could not participate in the weekly discussions unless they watched the video of that week (the icon of discussions would automatically be activated once students watch the video).

\section{Communication with Students}

There was the timing for online chatting with students for two hours a week. During chatting, students could ask the teacher any question related to the course. However, two reasons made this chatting postponed. Firstly, female students did not participate in these chatting sessions for two weeks. Secondly, chatting was only done by text with no voice or video chatting, which means time-consuming for writing long answers and explanations. Therefore, two WhatsApp groups were created; one for male students and the second for females. Within these groups, communication was very smooth and answering questions and providing explanations were very fast and effective. These groups remained active until the final exam.

\section{Weekly Participation}

Students had the freedom to participate in the course any day, any time during the week. They could register themselves as participating at any day suited them. This was required by the university regulations to ensure students were attending the course. The registration icon was automatically activated once students watched the video.

\section{Exams}

Mid-Term (20\%) and Final exams (40\%) were done electronically with students present in a computer lab. All questions were added to the question bank in the Moodle and then the system randomly distributed them. Questions were varied between True and False, Multiple choice, Short answers, and long answers, and terms. The system automatically graded True and False questions and Multiple-choice questions. During the exam, students could see a stopwatch indicating the remaining time and a legend indicating all the exam questions and highlighting the answered questions and the non-answered questions. Therefore, students could easily find the remaining questions and go to them through the link in the legend. Once they finished the exam, they could review their answers before submission. After submitting the answers students were not allowed to amend their answers. Besides, in case students forgot to submit their answers, the system automatically saved answers and submitted them once the time was complete.

\section{Assignments}

Two assignments were given to students in this course.

Published By:
Blue Eyes Intelligence Engineering and Sciences Publication (C) Copvriaht: All riahts reserved.

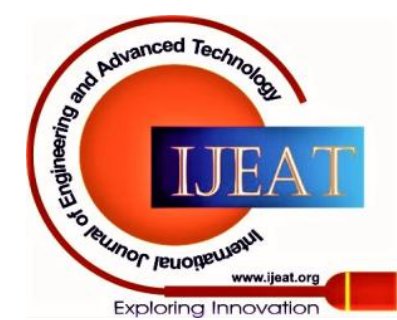




\section{Managing the Triangular Bond of the EBP for SQU Students Through the Proposed Test Model}

The first assignment was about conducting a simple search strategy (10\%) while the second one was about an advanced search strategy (10\%). Each assignment was attached with a badge, which was honored to each student scored nine or above out of 10 .

\section{Evaluating Students' Activities}

Moodle has the feature of reporting all students' activities from the first time they log into the course until the last day in the course. Therefore, the instructor could easily evaluate students' participation in the weekly discussions, how many times they watched videos or read attached documents and so on. By the end of the last week, the teacher exported a detailed report for each student to mark his or her activities during the semester.

\section{Student's Opinion about the Course}

By the end of the semester, a short survey was sent to students asking them to evaluate their experience in the course. All students answered the survey. The results showed a great appreciation for this course. One of the exciting results, which had the most significant appreciation, was the ability to see their grades for each course component and follow their progress in all course activities.

\section{THE PROPOSED TEST MODEL}

The engagement had been described as a significant track record of learning achievement. In early studies, student engagement was defined as a single dimension of behavioral component. On this basis, involvement was defined as the participation of students in various learning activities. The proposed test model was supposed to foster student's performance. By following the pattern of student's form (full log of students, midterm log and final exam log) and the way they engaged and behaved in the course activities. This model operated from the log file stored in Moodle based on collected student information through their profiles. To enhance students with mid and low performance, the instructor would re-prepare the course to ensure personalized learning according to the student's needs. In Fig. 2, the authors presented a model process test of the student engaging in a fully online course that was supposed to give an indicator of students' engagement.

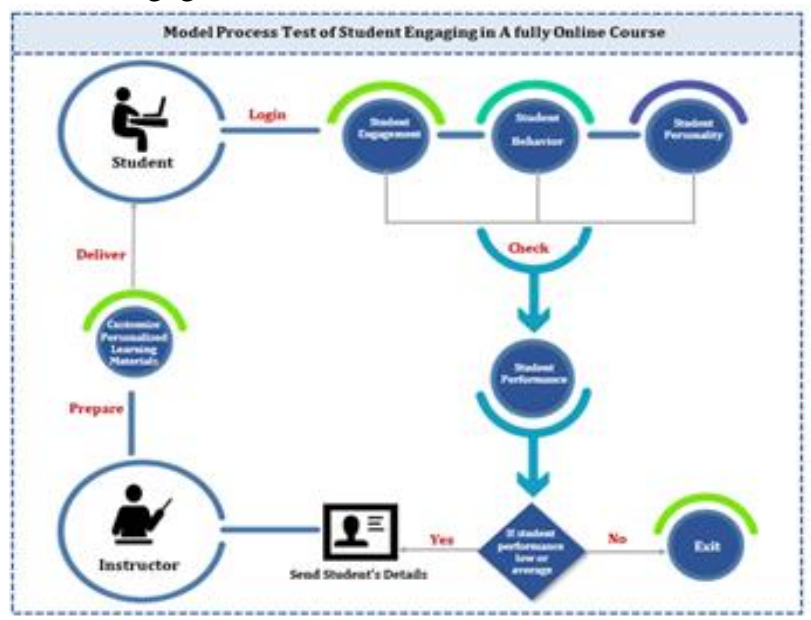

Fig. 2. Model Process Test of Student Engagement in A fully online course.

The scenario workflow of the proposed test model as follows:

\section{A. Student Engagement}

Student Engagement was considered as the most fundamental component in learning [21]. It was related to significant results such as grades and college completion at the higher education level psychological commitment and effort [22]. This paper related to student engagement with their effort and commitment given by students to their learning. The authors focused on how the students were engaging in the course using different activities and resources the instructor put it in the course. Further, after getting the log file of all students, the authors analyzed the data to categories the students into three different engagement levels to reach the low and medium performance between the students. Later on, the authors focused more on those selected students to enhance their performance by enhancing the course using the concepts of the learning object and personalized learning to answer the requirements of each student. Below a closer look on how Moodle as LMS offered details for each activity that student took in terms of the full and detailed reports. Example of student engagement in the fully online course "Search Strategies on the Internet." The authors took one student as a sample to prove the concept of engaging students in the various activities of the course. Fig. 3 shows a full report of the student engaged in the course activities such as through the attendance in each session per week, the forums and watching the introduction of the course. The Moodle system generated the total numbers of sessions the student attended each week, as it is highlighted in green in Fig. 3 below. Further, Fig. 4 illustrates a detailed report the same as a full report that mentions previously, but in more and more details for each activity the student takes.

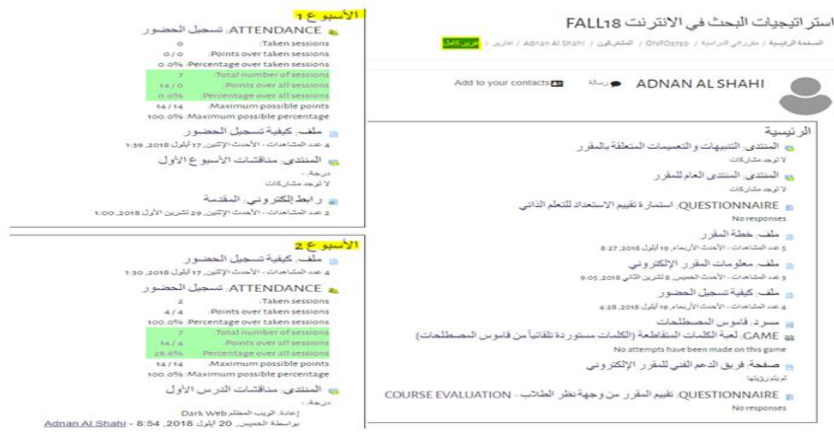

Fig. 3. Student Engagement in Course Activities (Full Report)

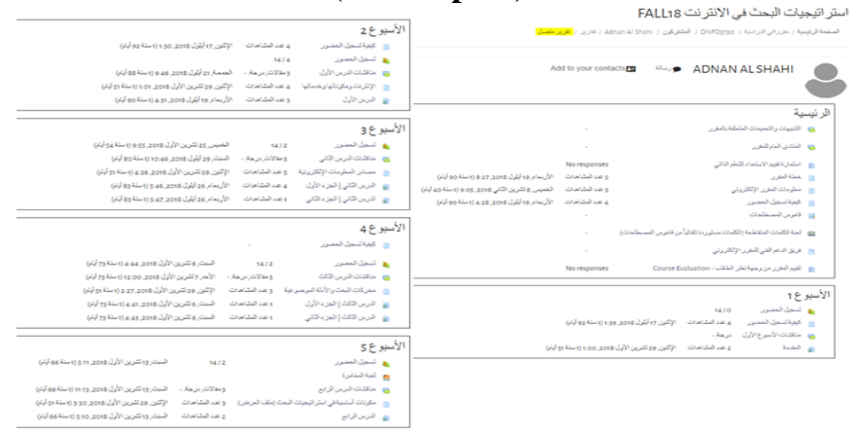

Fig. 4. Student Engagement in Course Activities (Detailed Report)

Published By:

Blue Eyes Intelligence Engineering and Sciences Publication

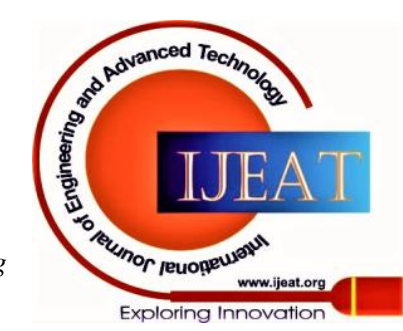




\section{B. Students Behavior}

Learning of student's behaviors were used as two-way interactions between students and the learning environment; these behaviors were intended to enhance what the students knew and could do [1]. Students would login to the "Search Strategies on the Internet" course via the Moodle platform using his/her username and password with the enrollment key that the instructor provided for only students to register in this course. Taking this action form, the students were considered behaving in the course through different actions they were doing.

\section{Students Personality}

McGeown and colleagues defined personality is "a set of underlying characteristics that determine how a person typically acts, thinks and feels" [23].

Knowing the basic requirements of students with various personality characteristics will help teachers identify acceptable teaching methods when teaching online courses [24].

\section{Student Performance}

Magnussen discovered that the behavior of the learners was positively related to performance [25]. The Moodle prepared reports of students logfile and recorded all their logs and course activities participation at the backend of the corresponding course. From those logs files, the authors received three different logs, which were full logs of the course, Midterm exam logs (including the time student spent while answering the exam and the grades) and Final exam (same attributes as Midterm exam logs). Based on analyzing the previous logs (More details given in Instrument section) instructor was able to improve the course to meet student's needs using the proposed test model and enhanced their performance before the end of the semester.

\section{E. Personalized Learning}

Personalized learning is the subject of the knowledge of the needs, abilities, and interests of each student, including the right to choose and talk to the learner about what, where and when to give flexibility and support to the best possible standards [26]. It is supposed to provide the instructors with the data and approaches needed to make better pedagogical choices to allow students to learn in their ways. If the Midterm exam is considered, after getting a clear overview of how each student behaved and engaged in course activities form at the beginning of the semester until the Midterm exam, the instructor could improve the course (for the remaining semester) to answer each student's needs in case of a personalized learning course. In this way, the instructor could use the test model process, which uses modern technologies to track student learning needs in the course of everyday teaching and learning activities.

\section{METHOD}

To test the proposed model, fifteen students from the undergraduate level at the College of Arts and Social Sciences selected for their tracking information to be used. The authors explain the process followed to analyze the data in the coming subsections below.

\section{A. Preparing Dataset}

The data received from Moodle consists of three excel files (Tables), which were:

a) Final Exam: it represented by the marks of the final exam of all students along with the time spent during the exam.

b) Mid Exam: it represented by the marks of the midterm exam of all students along with the time spent during the exam.

c) Activity: it represented by all different activities in the course for each student with details for example attendance, discussion viewed, submission files, chats with the instructor and course unit if were reviewed by students, if score report reviewed from student and external tool viewed by students, etc. "Final exam" and "Mid Exam" tables included required fields such as Student ID and the mark of the exam, while the "Activity" table contained: Student ID, Number of activities of each student and Level of Activity as shown in Fig.5 . These tables were derived from other tables through the primary key (i.e. Student ID).

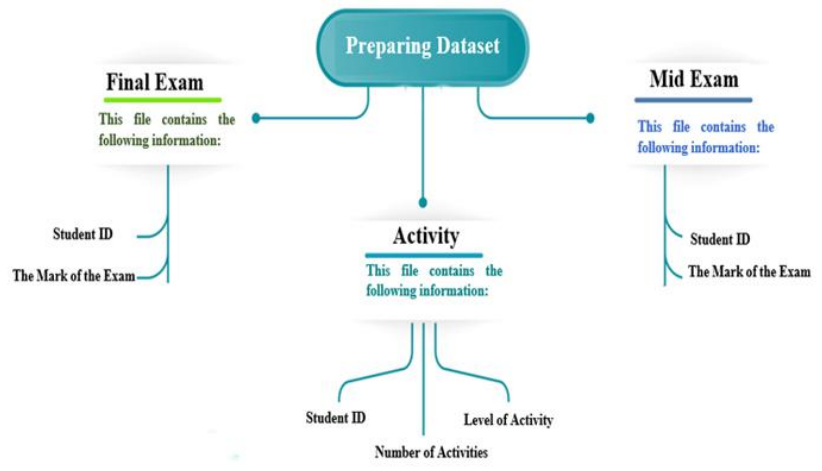

Fig. 5. Structure of the files used to prepare dataset.

\section{RESULT AND DISCUSSION}

As mentioned previously, the authors collected data from the following three tables:

Midterm Exam Excel File

Table- I: Students Marks of Midterm Exam

\begin{tabular}{|c|c|}
\hline Student ID & Mark/ 20 \\
\hline 1000 & 17.5 \\
\hline 1001 & 17.25 \\
\hline 1002 & 19.5 \\
\hline 1003 & 17.25 \\
\hline 1004 & 16.75 \\
\hline 1005 & 15.5 \\
\hline 1006 & 14.5 \\
\hline 1007 & 19.25 \\
\hline 1008 & 19.5 \\
\hline 1009 & 15.75 \\
\hline 1010 & 15.25 \\
\hline 1011 & 19.5 \\
\hline 1012 & 12.25 \\
\hline 1013 & 15.75 \\
\hline
\end{tabular}

Final Exam Excel File

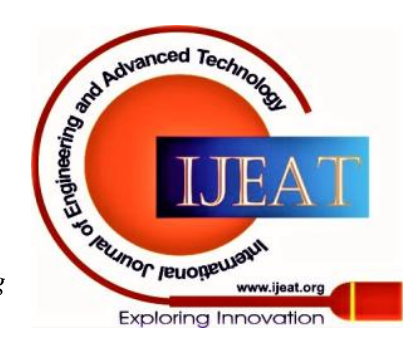



Table- II: Students Marks of Final Exam

\begin{tabular}{|c|c|}
\hline Student ID & Mark /40 \\
\hline 1000 & 38.5 \\
\hline 1001 & 31.5 \\
\hline 1002 & 39 \\
\hline 1003 & 34.5 \\
\hline 1004 & 29 \\
\hline 1005 & 28.75 \\
\hline 1006 & 29 \\
\hline 1007 & 29.5 \\
\hline 1008 & 38 \\
\hline 1009 & 34 \\
\hline 1010 & 38.5 \\
\hline 1011 & 38.5 \\
\hline 1012 & 30 \\
\hline 1013 & 25.5 \\
\hline
\end{tabular}

\section{A. Activities Column in Activity Excel File}

To check how the student's engaged in different activities of the course such as discussion, submitting assignments, playing games, attendance, exams etc. The below Table were used to represent all activities done by students.

Table- III: Students Activities

*(Note: This is only a part of the Table; it consists of 14775 records of all students in the course)

\begin{tabular}{|c|c|c|c|}
\hline Student ID & Event Context & Element & Forum \\
\hline 1005 & Forum: Alerts and circulars related to the course & Forum & The course unit instance list displayed \\
\hline 1013 & Course: Internet search strategies & Forum & Discussion viewed \\
\hline 1013 & Forum: Alerts and circulars related to the course & Forum & Discussion viewed \\
\hline 1013 & Forum: Alerts and circulars related to the course & Forum & Discussion viewed \\
\hline 1013 & Forum: Alerts and circulars related to the course & Forum & Discussion viewed \\
\hline 1004 & Forum: Alerts and circulars related to the course & System & View User Profile \\
\hline 1004 & Forum: Alerts and circulars related to the course & System & The course had been reviewed \\
\hline 1005 & Course: Internet search strategies & System & The course had been reviewed \\
\hline 1003 & Course: Internet search strategies & System & The course had been reviewed \\
\hline 1002 & Course: Internet search strategies & System & The course had been reviewed \\
\hline 1004 & Course: Internet search strategies & System & The course had been reviewed \\
\hline 1005 & Course: Internet search strategies & System & The course had been reviewed \\
\hline 1011 & Course: Internet search strategies & System & The course had been reviewed \\
\hline 1011 & Course: Internet search strategies & System & The course had been reviewed \\
\hline 1011 & Course: Internet search strategies & System & The course had been reviewed \\
\hline 1011 & Course: Internet search strategies & Course: Internet search strategies &
\end{tabular}

Based on the activities of students, the tables do not contain explicitly categorized columns for these features. Therefore, a new column for the categorized data was derived. This was presented in the following sections. Also, some changes as excluding unimportant columns were done. As study goal depends on the number of students' activities:

- An explicit numerical column was derived to contain the number of activities for each student: Activity

- An explicit categorized column was derived to include the number of activities for each student (Low, Mid, High): Activity Grade

These two columns were derived as follow:

First: Drive Activity Column

Table- IV: Conducting subtotal to calculate the number of activities for each student

\begin{tabular}{|c|c|}
\hline Student ID & No. of Activities \\
\hline 1000 & 910 \\
\hline 1001 & 608 \\
\hline 1002 & 1410 \\
\hline 1003 & 1309 \\
\hline 1004 & 737 \\
\hline 1005 & 583 \\
\hline 1006 & 713 \\
\hline
\end{tabular}

\begin{tabular}{|c|c|}
\hline 1007 & 1515 \\
\hline 1008 & 1167 \\
\hline 1009 & 1117 \\
\hline 1010 & 1000 \\
\hline 1011 & 1401 \\
\hline 1012 & 395 \\
\hline 1013 & 1106 \\
\hline Total No. of Activities & 13971 \\
\hline
\end{tabular}

As it was shown in Table IV, the number of activities for each student was calculated using the SUBTOTAL function in Excel. The SUBTOTAL function returned an aggregate result for supplied values (in our data for activities of the student). SUBTOTAL could return a SUM, AVERAGE, COUNT, MAX, and others (for our step, the COUNT was used). To use SUBTOTAL [27]:

1. Sort the worksheet by the activity's column data (you want to subtotal of it).

2. Select the tab Data, then click the command Subtotal as it is shown in Fig. 6. Use the Subtotal command allows you to automatically create groups and use the common function COUNT to help summarize your data.

\section{Published By:}

Blue Eyes Intelligence Engineering and Sciences Publication

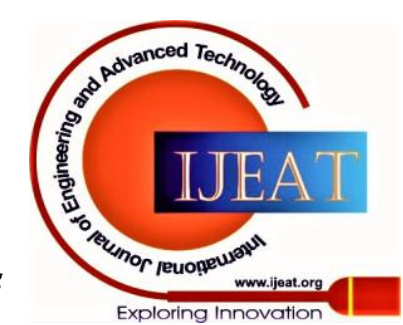




\section{Managing the Triangular Bond of the EBP for SQU Students Through the Proposed Test Model}

3. From the dialog box Subtotal. Click the drop-down arrow at each change in the field to pick the column you wish to subtotal. In our work, Activities were selected.

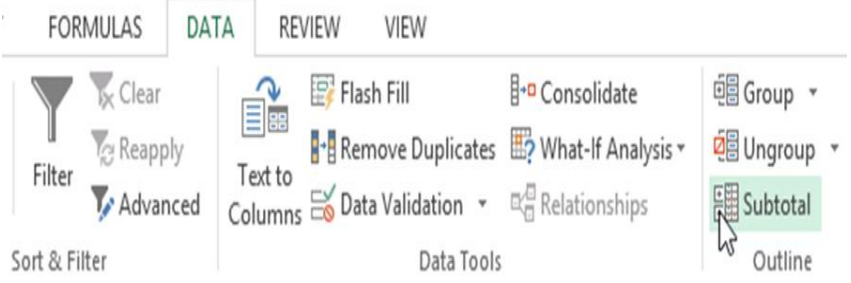

Fig. 6. Subtotal command.

A.Click the drop-down arrow to pick the Use function you want to use. In our work, COUNT was selected to count the number of activities.

B. In the Add subtotal to the field, select the column where you want the calculated subtotal to appear. In our work, Activities were selected.

C. Click OK when you are satisfied with your selections.

D. The result of COUNT would appear as shown in Table IV.

Second: Drive the categorized Activity Column (Level of Activity)

Table- V: Calculate Activities column in Activity Excel file

\begin{tabular}{|c|c|c|}
\hline Student ID & No. of Activities & Level of Activity \\
\hline 1000 & 910 & Mid \\
\hline 1001 & 608 & Low \\
\hline 1002 & 1410 & High \\
\hline 1003 & 1309 & High \\
\hline 1004 & 737 & Low \\
\hline 1005 & 583 & Low \\
\hline 1006 & 713 & Low \\
\hline 1007 & 1515 & High \\
\hline 1008 & 1167 & High \\
\hline 1009 & 1117 & Mid \\
\hline 1011 & 1401 & High \\
\hline 1012 & 395 & Low \\
\hline 1013 & 1106 & Mid \\
\hline 1010 & 1000 & Mid \\
\hline
\end{tabular}

As shown in Table V, "Activity" was represented by a numerical type that was produced from the previous step. It was converted to categories (Low, Mid, High). The concept used here is that, if the number of activities of each student was more than 1141 means his/her engagement was High and if the number of activities was between 768-1141 means his/her engagement was Mid and so on. The conversion was done based on dividing the interval between the maximum value (Highest) and minimum value (Lowest) as the following steps:

- Detect the minimum value (i.e. 395).

- Detect the maximum value (i.e. 1515).

- Calculate the range (interval) between the minimum and maximum by subtracting the minimum from maximum $(1515-395=1120)$.

- Calculate the value of each sub-interval by dividing the range by 3 , $(1120 \div 3=373)$.

- Calculate the interval of Low by $(395+373=768$ and less $)$

- Calculate the interval of Mid by $(768+373=1141)$ which was over 768 to 1141

- The interval of High was over than 1141.

- By these steps, the activities for each student were represented by (Low, Mid, High) instead of activities details.

\section{B. Is there a relationship between the number of} activities in the course for each student and Total mark?

To clarify this relationship using the Excel tables "Activity", "Final Exam" and "Midterm Exam," (Table VI) using a correlation chart, the authors had to transform the data into homogeneous forms as numerical data in the same rang. So, the format of (Student ID and No. of Activity) were transformed into a new format related to the mark (Table VIII). In addition, the total mark (60 marks) of students was calculated as the summation of the midterm exam (20 marks) and final exam (40 marks).

Table- VI: Activities Data before Transformation

\begin{tabular}{|c|c|c|c|c|}
\hline Student ID & $\begin{array}{c}\text { No. of } \\
\text { Activity }\end{array}$ & $\begin{array}{l}\text { Level of } \\
\text { Activity }\end{array}$ & $\begin{array}{c}\text { Mid } \\
\text { Mark }\end{array}$ & $\begin{array}{l}\text { Final } \\
\text { Mark }\end{array}$ \\
\hline 1000 & 910 & Mid & 17.5 & 38.5 \\
\hline 1001 & 608 & Low & 17.25 & 31.5 \\
\hline 1002 & 1410 & High & 19.5 & 39 \\
\hline 1003 & 1309 & High & 17.25 & 34.5 \\
\hline 1004 & 737 & Low & 16.75 & 29 \\
\hline 1005 & 583 & Low & 15.5 & 28.75 \\
\hline 1006 & 713 & Low & 14.5 & 29 \\
\hline 1007 & 1515 & High & 19.25 & 29.5 \\
\hline 1008 & 1167 & High & 19.5 & 38 \\
\hline 1009 & 1117 & Mid & 15.75 & 34 \\
\hline 1010 & 1000 & Mid & 15.25 & 38.5 \\
\hline 1011 & 1401 & High & 19.5 & 38.5 \\
\hline 1012 & 395 & Low & 12.25 & 30 \\
\hline 1013 & 1106 & Mid & 15.75 & 25.5 \\
\hline
\end{tabular}

The transformation process was done as follows:

1. Column (Student ID) was transformed to (T-Student ID) by renumbering the students from 1 to 14 and set them in the same order of midterm exam.

2. Column (No. of Activity) was transformed to (T-Activity) by using the Level of Activity column and give a represented number for each interval; the values $(60,40,20)$ are approximated chosen values to represent the " Activity " as follows:

- Low was transformed to 20 (The minimum rate of activities).

- Mid was transformed to 40.

- High was transformed to 60.

Published By:

Blue Eyes Intelligence Engineering and Sciences Publication

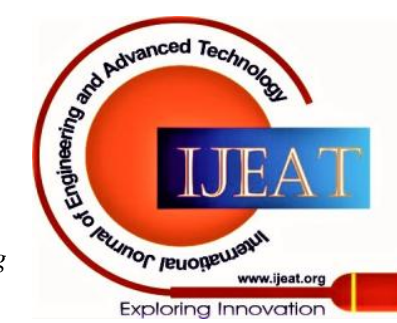


We assumed that these numbers (60, 40 and 20) were estimated numbers corresponding to the level of engagement of students with the Moodle, as brief in Table VII.

Table- VII: T-Activity with corresponding No. of Activity

\begin{tabular}{|c|c|}
\hline T-Activity & No. of Activity \\
\hline $\mathbf{6 0}$ & 1141 and more \\
\hline
\end{tabular}

\begin{tabular}{|c|c|}
$\mathbf{4 0}$ & $768-1141$ \\
\hline $\mathbf{2 0}$ & 768 and less \\
\hline
\end{tabular}

Note: The Level of Activity was produced by dividing the interval between the maximum and minimum activity by three, then split the interval to equal durations, as we mentioned previously.

Table- VIII: Activities Data after Transformation

\begin{tabular}{|c|c|c|c|c|c|c|c|}
\hline Student ID & T-Student ID & Activity & T-Activity & Level of Activity & Mid Mark & Final Mark & Total Mark \\
\hline 1000 & 1 & 910 & 40 & Mid & 17.5 & 38.5 \\
\hline 1001 & 2 & 608 & 20 & Low & 17.25 & 31.5 \\
\hline 1002 & 3 & 1410 & 60 & High & 19.5 & 39 \\
\hline 1003 & 4 & 1309 & 60 & High & 17.25 & 34.5 \\
\hline 1004 & 5 & 737 & 20 & Low & 16.75 & 29 \\
\hline 1005 & 6 & 583 & 20 & Low & 15.5 & 28.75 \\
\hline 1006 & 7 & 713 & 20 & Low & 14.5 & 29 \\
\hline 1007 & 8 & 1515 & 60 & High & 19.25 & 45.75 \\
\hline 1008 & 9 & 1167 & 60 & High & 19.5 & 29.5 \\
\hline 1009 & 10 & 1117 & 40 & Mid & 15.75 & 38 \\
\hline 1010 & 11 & 1000 & 40 & Mid & 15.25 & 34 \\
\hline 1011 & 12 & 1401 & 60 & High & 19.5 & 38.5 \\
\hline 1012 & 13 & 395 & 20 & Low & 12.25 & 38.5 \\
\hline 1013 & 14 & 1106 & 40 & Mid & 15.75 & 39.75 \\
\hline
\end{tabular}

After the transformation process, the correlation chart is drawn using a scatter chart in excel and shown in Fig. 7. The correlation chart a regular relationship between No. of Activities and the total mark.

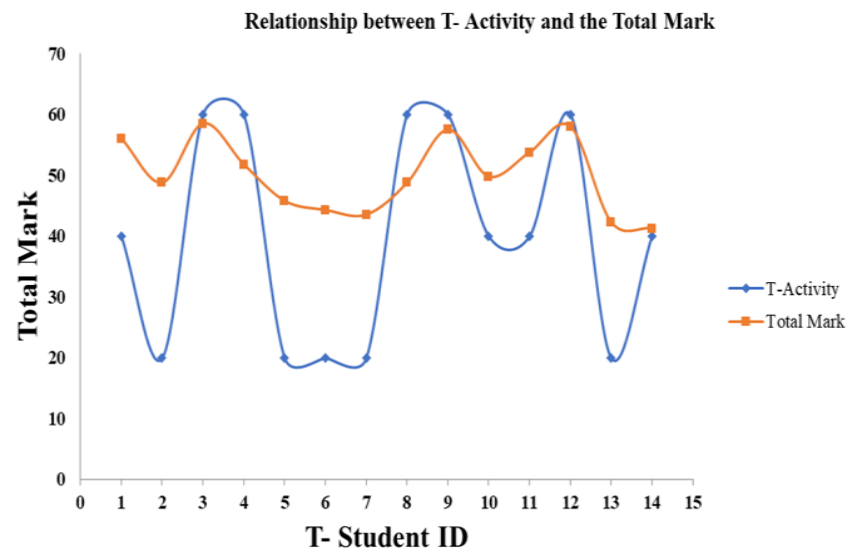

Fig. 7. Correlation chart between Total Mark and T-Activity.

It can often be considered a positive correlation where the student's activities on the educational platform (Moodle) correspond to his/her total mark. As example:

- Most students with a high activity rate achieved a high score (Highlighted in Blue).

- Only two students with a high score, their activity rate was not high (Mid level of activity). (Highlighted in gray).

- The best student of the students' group had the highest total mark.

- Based on Fig.7, usually the curve of T- Activity goes with the curve of the total mark with positive behavior. That means the performance of students had a strong relationship with his/her engagement with fully online course activities through Moodle [28].

\section{Enhancement of Student Performance using Reusable Multipurpose Learning Object Model (RMLOM)}

One aspect of a smart learning environment in the smart cities was to take care of students via understanding their behavior. This could be achieved by the introduction of an active educational environment [7]. It had been noted that the main purpose of enhancement of student performance was based on the previous results: understand that students were different in their grades (Midterm and Final exams), different in engaging in course activities and different in the level of understanding. There were three groups of students in general, Low, Mid, and High. Also, their chosen learning styles were different; some students learnt best from reading, while others prefer the audio or video form. Hence, offering the same learning materials to all these groups would lead to inconsistent outcomes. It leaded to insufficient conditions towards active learning [29]. In order to manage those differences suitably in a way that was supposed to meet the student's requirements and would lead to better performance depending on activities, exams, etc. The authors suggest using Personalized Learning (PL) and Reusable Multipurpose Learning Object Model (RMLOM) [30] to improve the course contents.

Reasons to use (PL) in a fully online course

- Addressing each student's needs

- Engaging students in various course activities

- Assisting students in meeting academic standards

- Enhancing student performance

- Letting students decide the learning style they want

Published By:

Blue Eyes Intelligence Engineering and Sciences Publication

(C) Copvriaht: All riahts reserved.

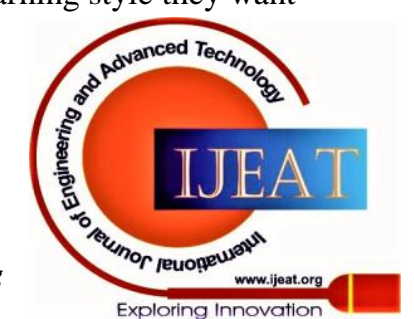




\section{How to use RMLOM for PL course contents}

A learning object was defined as building blocks that could be combined to create lessons, modules or courses. $\mathrm{LO}$ could be shown in different sets of media such as text, animation, audio and video [31]. Developing a course from scratch that fits each student's needs was time-consuming. Creating a course should, therefore, be based primarily on the use of the modular type of learning material called Learning Object [29]. Using Reusable Multipurpose Learning Object Model (RMLOM) would enhance the processes of online learning. This model used a sequencer to create any course or facet of a course dynamically through the RMLOM reusable components. The model allowed the instructor to have the ability to determine the outlines of their courses. This would also encourage the instructor to plan courses for each student or group of them. In addition, the content should be built to support Personalized Learning by offering the same learning objects in various media such as video, text or audio. Accordingly, students could pick whatever medium they want to use in their learning process while using the PL as Fig. 8 shows.

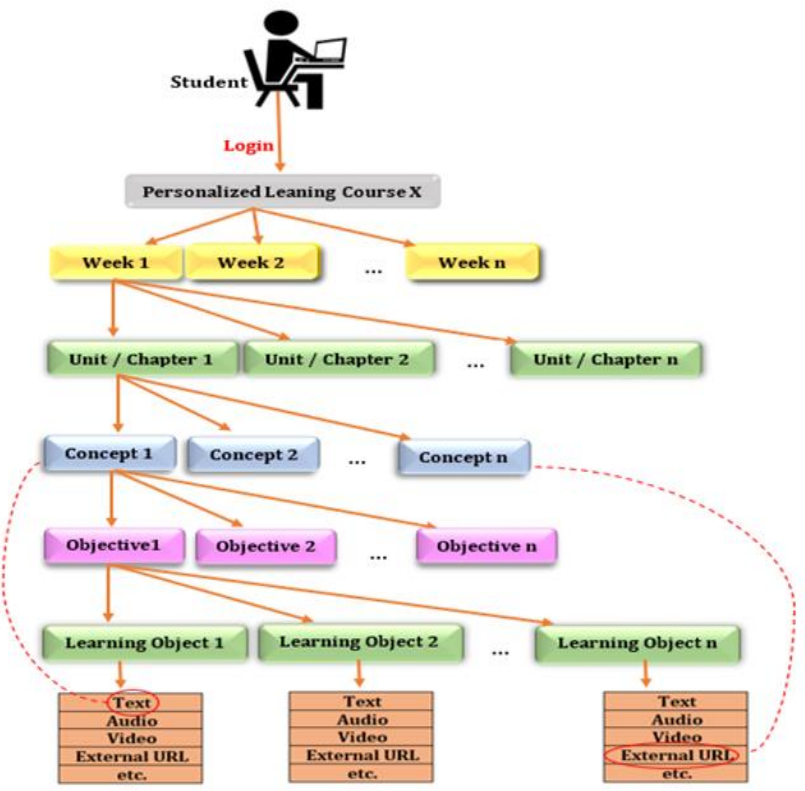

Fig. 8. A fully online personalized learning course with the support of Reusable Multipurpose Learning Object Model (RMLOM)

For the course organization, Week/Unit or Chapter/ Concept/ Objective/ LO the sequence of the information was critical because the student could not proceed to the next component without any idea about its prerequisites. In order to do this for each component (i.e. Week, Unit or Chapter/, Concept, Objective and LO) a prerequisite must be specified. Therefore, the student could not take the component until the prerequisite was completed) [30]. If the instructor implements such a model while preparing the course outline, this was supposed to let students choose their own pathway of learning during the course. This may also encourage them to engage in activities as well as improve their performance. The cause of RMLOM would satisfy the preferences of the students. Also, students would find it easy to follow this model in a fully online course. That was because it was organized in personalized mode to facilitate learning.

\section{CONCLUSION}

This paper offered a model for student engagement by using available data in Moodle (Logfile of the course) to analyze student engagement and performance. The results showed that most students with a high activity rate achieved a high score in the course, which mean there is a relationship between the number of activities in the course for each student and Total mark Hence, the setting outline of courses must be suitable for the learning style, skills, and interests of each student in order for each to do well in any chosen course. While this paper was not intended to establish whether the correlation between the patterns of student engagement and their performance was causal. Using this model encouraged instructors to engage students through LMSs (i.e., Moodle) in various activities, thus enabling students to participate in the online courses effectively [28]. Technologically, researchers were making good progress in realizing student's engagement in an online course based on their needs. In a way that helped the instructor to consider how each student engaged and behaved during the courses chosen, and what would be the overall performance behind this engagement. It should be note that, the number of students in the course used in this paper was 14 students only enrolled in it. As future work, the authors would try to choose other courses with more significant numbers of students to ascertain more factors that affect students' performance while learning online courses.

\section{ACKNOWLEDGMENT}

The authors wish to thank Sultan Qaboos University, College of Science and the Department of Computer Science. This work is under Prof. Zuhoor Al-Khanjari's supervision supported as a part of a scholarship of Doctoral Program from the Sultan Qaboos University. The thanks also extended to Dr. Jamal Al Salmi for his collaboration in terms of using all data of his course "Search Strategies on the Internet" as a case study in this paper.

\section{REFERENCES}

1. I. Nurjaman, "The Challenge of Implementing Smart Learning: Learning Behavior Readiness for Indonesian Students", International Journal of Education, Information Technology, and others, 2018, 1(2), 25-29.

2. M. Epstein, M. Atkins, D. Cullinan, K. Kutash, and K. Weaver, "Reducing behavior problems in the elementary school classroom", IES Practice Guide, 2008, 20(8), 12-22.

3. L. Lee, and K. Hao, "Designing and evaluating digital game-based learning with the ARCS motivation model, humor, and animation", International Journal of Technology and Human Interaction (IJTHI), 2015, 11(2), 80-95.

4. C. Lee, Y. Cheng, S. Rai, and A. Depickere, "What affect student cognitive style in the development of hypermedia learning system?", Computers \& Education, 2005, 45(1), 1-19.

5. M. Zorrilla, S. Millan, and E. Menasalvas, "Data web house to support web intelligence in e-learning environments", In 2005 IEEE International Conference on Granular Computing, Beijing, China, 2005, July, (Vol. 2, pp. 722-727).

6. R. Estacio, and Jr. Raga, "Analyzing students online learning behavior in blended courses using Moodle", Asian Association of Open Universities Journal, 2017, 12(1), 52-68.

Published By:

Blue Eyes Intelligence Engineering and Sciences Publication

(C) Copvriaht: All riahts reserved.

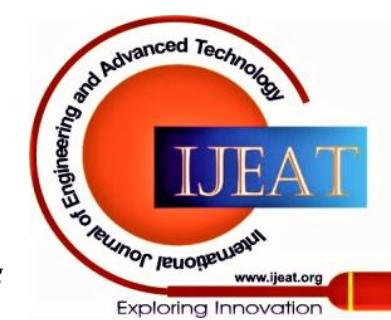




\section{Managing the Triangular Bond of the EBP for SQU Students Through the Proposed Test Model}

7. I. Al-Kindi, and Z. Al-Khanjari, "The Smart Learning Management System (SLMS)", Free and Open Source Software Conference (FOSSC-2019), Muscat, Sultanate of Oman, 2019, February, pp. 32-35.

8. M. Dixson, "Measuring student engagement in the online course: The Online Student Engagement scale (OSE)", Online Learning, 2015, 19(4), $\mathrm{n} 4$.

9. M. Guilloteaux, "Student engagement during EFL high school lessons in Korea: An experience-sampling study", Foreign Languages Education, 2016, 23(1), 21-46.

10. K. Manwaring, R. Larsen, C. Graham, C. Henrie, and L. Halverson, "Investigating student engagement in blended learning settings using experience sampling and structural equation modeling", The Internet and Higher Education, 2017, 35, 21-33.

11. T. Nguyen, M. Cannata, and J. Miller, "Understanding student behavioral engagement: Importance of student interaction with peers and teachers", The Journal of Educational Research, 2018, 111(2), 163-174.

12. M. Hussain, W. Zhu, W. Zhang, and S. Abidi, "Student Engagement Predictions in an e-Learning System and Their Impact on Student Course Assessment Scores", Computational intelligence and neuroscience, 2018, https://doi.org/10.1155/2018/6347186.

13. N. Mirriahi, J. Jovanovic, S. Dawson, D. Gašević, and A. Pardo, "Identifying engagement patterns with video annotation activities: A case study in professional development", Australasian Journal of Educational Technology, 2018, 34(1).

14. F. Martin, and D. Bolliger, "Engagement matters: Student perceptions on the importance of engagement strategies in the online learning environment", Online Learning, 2018, 22(1), 205-222.

15. S. Wasik, J. Barrow, C. Royal, R. Brooks, L. Dames, L. Corry, and C. Bird, "Online Counselor Education: Creative Approaches and Best Practices in Online Learning Environments", Research on Education and Psychology, 2019, 3(1), 1-1.

16. J. Lee, H. Song, and A. Hong, "Exploring factors, and indicators for measuring students' sustainable engagement in e-learning", Sustainability, 2019, 11(4), 985.

17. Z. Al-Khanjari, and I. Al-Kindi, “ Integrating MOOC with Open Source Moodle: The New Direction of Learning at Sultan Qaboos University",.In 2018 International Conference on Innovations in Information Technology (IIT), Al Ain, United Arab Emirates, 2018, January , (pp. 47-51). IEEE.

18. S. Dias, and J. Diniz, "Towards an enhanced learning management system for blended learning in higher education incorporating distinct learners' profiles ", Journal of Educational Technology \& Society, 2014, 17(1), 307-319.

19. I. Al-Kindi, and Z. Al-Khanjari, "Collaborative learning: A new horizon for E-learning in Sultan Qaboos University using concepts of MOOC and cloud computing", In 2017 6th International Conference on Information and Communication Technology and Accessibility (ICTA), Muscat, Sultanate of Oman, 2017, April, (pp. 1-6). IEEE.

20. J. Mostow, and J. Beck, "Some useful tactics to modify, map and mine data from intelligent tutors", Natural Language Engineering, 2006, 12(2), 195-208.

21. G. Sinatra, B. Heddy, and D. Lombardi, "The Challenges of Defining and Measuring Student Engagement in Science", Educational Psychologist, 2015, 50:1, 1-13, DOI: 10.1080/00461520.2014.1002924

22. S. Lamborn, F. Newmann, and G. Wehlage, "The significance and sources of student engagement", Student engagement and achievement in American secondary schools, 1992, 11-39.

23. S. McGeown, D. Putwain, E. Simpson, E. Boffey, J. Markham, and A. Vince, "Predictors of adolescents' academic motivation: Personality, self-efficacy and adolescents' characteristics", Learning and Individual Differences, 2014, 32, 278-286.

24. K. Bhagat, Y. Wu, and C. Chang, "The impact of personality on students' perceptions towards online learning", Australasian Journal of Educational Technology, 2019, 35(4).

25. T. Magnussen, "Learning behavior, strategy and performance: a structural equation modeling study", (Master's thesis), University of Oslo, 2010.

26. S. Johns, and M. Wolking, "The Core Four of Personalized Learning: The Elements You Need to Succeed", Education Elements, https://www.edelements.com/hubfs/Core_Four/Education_Elements_C ore_Four_White_Paper.pdf, [Accessed January 29, (2020)].

27. Excel 2016 - Groups and Subtotals. https://edu.gcfglobal.org/en/excel2016/groups-and-subtotals/1/, [Accessed August 21, (2020)].

28. Z. Al-Khanjari, and I. Al-Kindi, "Proposing the EBP Smart Predictive Model Towards Smart Learning Environment", Journal of Talent Development and Excellence, 2020, 12(2s), pp2422-2438.
29. Z. Al-Khanjari, S. Kutti, and F. Al-Mahri, "RMLOM: Reusable Multipurpose Learning Object Model", In Proceedings of The 4th International Conference on Information Systems, Bangkok, Thailand, 2010, March, (pp. 11-13).

30. F. Al-Mahri, "Master Thesis: Learning Content Management System in support of Personalized Learning", Master of Science, Sultan Qaboos University, Muscat, Sultanate of Oman, 2008.

31. A. Chikh, "A general model of learning design objects", Journal of King Saud University-Computer and Information Sciences, 2014, 26(1), 29-40. https://doi.org/10.1016/j.jksuci.2013.03.001

\section{AUTHORS PROFILE}

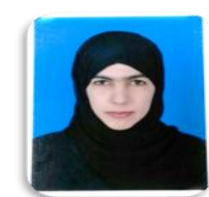

Iman Al-Kindi is currently a $\mathrm{PhD}$ candidate in the Department of Computer Science, College of Science at Sultan Qaboos University, Sultanate of Oman. She received her BSc in software Engineering from Higher College of Technology, Sultanate of Oman, and MSc in Computer Science from Sultan Qaboos University, Sultanate of Oman. She has worked as a visiting lecturer for more than one year at Sultan Qaboos University, Sultanate of Oman.

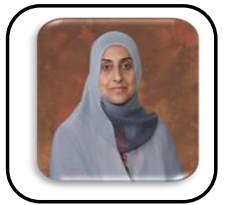

Zuhoor Al-Khanjari is a professor in software engineering. She worked as the HOD of the Department of Computer Science, College of Science at Sultan Qaboos University, Sultanate of Oman. She received her BSc in mathematics and computing from Sultan Qaboos University, Sultanate of Oman, MSc and $\mathrm{PhD}$ in computer science (software engineering) from the University of Liverpool, UK. Her research interests include software engineering, software testing techniques, database management, e-learning, m-learning and mobile computing. Currently, she is the coordinator of the software engineering group in the Department of Computer Science, Sultan Qaboos University, Sultanate of Oman. Also, she is coordinating e-learning facilities in the same department. She is a member of the editorial board of the International Arab Journal of Information Technology (IAJIT) and a member of the executive committee of the International Arab Conference on Information Technology (ACIT).

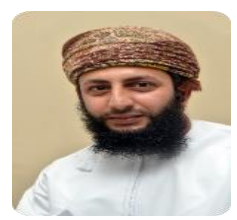

Jamal Alsalmi is Assistant Professor and Head of Information Studies Department, College of Arts and Social Sciences, Sultan Qaboos University. He received his BSc in in Library and Information Science from Sultan Qaboos University, Sultanate of Oman, MSc in Information Management, from Curtin University of Technology, Australia and PhD in Knowledge Management, Victoria University of Wellington, New Zealand. His research interests include Knowledge sharing using new technologies, National and international digital repositories and Different software that are linked to information profession.
Blue Eyes Intelligence Engineering and Sciences Publication

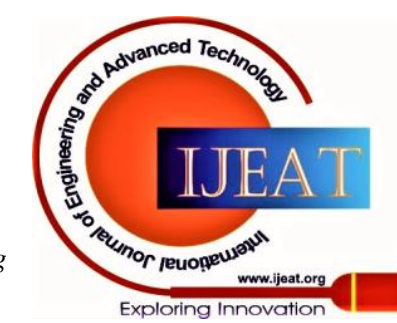

Exploring Innovation 